\title{
Improving The Antioxidant Activity of Sodium Alginate from Sargassum sp. by Thermal Heating and Chemical Methods
}

\author{
Mila Safitri Rizfa, Ervia Yudiati*, Diah Permata Wijayanti \\ Marine Science Department, Faculty of Fisheries and Marine Science, Diponegoro University \\ JI. Prof. H. Soedarto, SH., Tembalang, Semarang, 50275, Indonesia \\ Email: eyudiati@gmail.com
}

\begin{abstract}
The relationship between molecular structure and bioactivity was evaluated for sodium alginates obtained under different degradation treatment (raw alginates, heat-treated, and chemical-treated) from Sargassum sp. This study was conducted to identify the antioxidant activities of the degraded sodium alginate from Sargassum sp. compared to raw extract. Raw alginate as the control treatment was dried overnight at $60^{\circ} \mathrm{C}$, while heat-treated was heated raw alginate at $140^{\circ} \mathrm{C}$ in a laboratory oven (4.5 hours). Two chemical-treated were applied. Raw alginate added hydrogen peroxide and raw alginat with hydrogen peroxide plus ascorbic acid. These treatments were replicated three times. All the parameters were evaluated spectrophotometrically. The spectroscopy results from the degradation methods showed a new absorbance spectra pattern. The FT-IR spectrum revealed that treatment affects the structure of the alginates. Heat treated and chemical treated sodium alginates showed non significantly different on DPPH radical scavenging activity. Meanwhile, the combination of alginate and hydrogen peroxide treatment was at the lowest scavenging ability. Therefore, alginate oligosaccharides (AOS) produced by heating or adding chemical reagents could be considered as a stronger antioxidant than raw alginate, which may be applied in the industry and biomedical.
\end{abstract}

Keywords: antioxidant activity, Sargassum, sodium alginate, degradation

\section{INTRODUCTION}

Alginates consist of $(1,4)$ linked $\beta-D$ mannuronic acid (M) with ${ }_{1}^{4} C$ ring formation and a-L-guluronic acid (G) with ${ }_{4}^{1} \mathrm{Cring}$ conformation (Fenoradosoa et al., 2010). Alginates, commonly derived from brown algae (Phaeophyceae), have been widely investigated by many researchers for a possible new alternative in the food industry and medical approach (Cherng, 2018). The recent studies revealed that polysaccharides from Sargassum sp. possess multiple functions, such as antitumor (Chen, 2017), immunomodulatory (Borazjani et al., 2017), emulsifying agents (Fawzy et al., 2017), antioxidant activity (Sellimi et al., 2015). Due to the excellent functions, research continues to develop the optimal results of alginate polysaccharides. There have been many research results related to decrease in molecular mass alginate using depolymerization (Sari-Chmayssem et al.,
2016; Liu et al., 2019; Dodero et al., 2020). Alginate which has undergone a depolymerization process called alginate oligosaccharides (AOS) (Addina et al., 2020). AOS has been shown to have antioxidant properties (Kelishomi et al., 2016; Chen et al., 2016; Yudiati et al., 2018).

The antioxidant properties are the ability of a compound to inhibit and catch on reactive free radicals in the body by neutralizing the free radical molecules (Kale \& Nabunome, 2019). Research conducted by Chen et al. (2016) and Yudiati et al. (2018) proved that the depolymerization process can improve the ability of AOS antioxidants. Alginate oligosaccharides, oligomers containing 2 to 25 monomers, can be produced by splitting of the glycosidic bonds. AOS can be obtained via physical or chemical methods, enzymatic methods, fermentation, organic synthesis, and biosynthesis (Liv et al., 2019). 
Referring to the AOS obtained using chemical methods, as has been done by Zhang et al. (2013) and Chen et al. (2016), stated that hydroxyl radical $\left(\mathrm{HO}^{\circ}\right)$ as a free radical can degrade polysaccharides by attacking and separating glycosidic bonds into powerful oxidants with short-lived. The reaction is could be obtained from $\mathrm{H}_{2} \mathrm{O}_{2}$ with a reduced transition metal ion. Ascorbic acid is also able to reduce hydrogen peroxide to produce hydroxyl radicals in the presence of trace metals. Therefore, the combination of hydrogen peroxide with ascorbic acid has attracted interest in the degradation of polysaccharides. On the other hand, AOS uses the heating method is reported by Yudiati et al. (2018), which is also able to improved antioxidants of Sargassum polycystum in $4.5 \mathrm{~h}$ treatment $(20.07 \%)$.

Refers to the simplest and availability of tools and materials for degradation methods, researchers used physical (heat-treated) and chemical $\left(\mathrm{H}_{2} \mathrm{O}_{2} ; \quad \mathrm{H}_{2} \mathrm{O}_{2}+\right.$ ascorbic acid $)$ method. Besides, these two methods are more cost-effective and accessible compared to the other methods (Kelishomi et al., 2016). Herein, the antioxidant activity of the degraded sodium alginate from Sargassum sp. is compared with raw sodium alginate extract.

\section{MATERIALS AND METHODS}

\section{Raw sodium alginate extraction}

The dried and powdered materials $(20$ g) of Sargassum sp. were extracted with $\mathrm{Na}_{2} \mathrm{CO}_{3} 5 \%$ solution in $500 \mathrm{~mL}$ aqueous volume and $\mathrm{pH}$ was neutralized to 7 using $\mathrm{HCl}$. The sample was kept and macerated at room temperature for $24 \mathrm{~h}$ with magnetic stirrer extraction. Then, the solution was filtered, $0.13 \mathrm{M} \mathrm{KCl}$ was added and followed by $96 \%$ ethanol in 1:1 volume, stirred well. Centrifugation was then performed for $7 \mathrm{~min}$ at $3500 \mathrm{rpm}$. After centrifugation, the pellet was collected and dried overnight at $60^{\circ} \mathrm{C}$ (Yudiati \& Isnansetyo, 2017). This method was subjected to Treatment A.

\section{Degradation of raw sodium alginate}

There were two types of degradation. The first was used for thermal degradation.
The raw sodium alginate powder was heated using an oven at $140 \circ \mathrm{C}$ for $4.5 \mathrm{~h}$ (Yudiati et al 2016). This subjected to treatment $B$. The later was used chemical compound. The raw alginate $(1.0 \mathrm{~g})$ was dissolved in $200 \mathrm{~mL}$ distilled water, then added $\mathrm{H}_{2} \mathrm{O}_{2}$ (Treatment C) and ascorbic acid plus $\mathrm{H}_{2} \mathrm{O}_{2}$ as Treatment $\mathrm{D}$ (molar ratio 1:1) directly into the solution. Afterward, the solution was heated at $51{ }^{\circ} \mathrm{C}$ for $1.6 \mathrm{~h}$. The solution was filtered and removed the pellets. The sample solution was precipitated by adding $96 \%$ ethanol (ratio 1:3, $\mathrm{V} / \mathrm{V}$ ). Next, the solution was then centrifuged for $10 \mathrm{~min}$ at $8000 \mathrm{rpm}$ (Chen et al., 2016). This treatment were replicated three times and aimed to reduce the molecular weight of alginate to facilitate the dissolution process and increase the ability of antioxidants.

\section{UV-visible spectroscopy}

The depolymerization process was detected by UV-visible spectroscopy. Aqueous solutions of alginate samples were prepared with distillation water at a concentration of $0.01 \quad(\mathrm{w} / \mathrm{V})$. UV-visible spectroscopy of raw alginate, heat-treated, and chemical-treated alginates were performed by ShimadzU UV-1601 UV-VIS Spectrophotometer in $200-400 \mathrm{~nm}$ range (Yudiati et al., 2018).

\section{Fourier-Transform IR (FT-IR) spectroscopy}

The FT-IR spectra of alginates were recorded in the 4000-500 cm-1 region using a Thermo Nicolet 380 FTIR (Germany). Preparation was done by mixing the samples with $\mathrm{KBr}$ in pellets formation $(10 \% \mathrm{~W} / \mathrm{W})$ (Yudiati et al., 2018).

\section{Determination of DPPH maximum absorbance}

DPPH was weighed for $2 \mathrm{mg}$ and dissolved with $50 \mathrm{~mL}$ of ethanol $(0.1 \mathrm{mM})$. The solution is homogenized and incubated for 30 min in a dark place. The solution of DPPH 0.1 $\mathrm{mM}$ was pipetted at $4 \mathrm{~mL}$. Absorbance was measured by ShimadzU UV-1280 UV-VIS spectrophotometer in 400-800 nm wavelength range (Chen et al., 2016).

\section{The assessment of antioxidant activity}

An antioxidant activity using the method of Chen et al. (2016) with 
modification of concentration and incubation time. The alginates were diluted with a concentration of $10,20,30,40,50$, and $100 \mathrm{ppm}$. Each sample was taken $2 \mathrm{~mL}$ and added a DPPH solution $(2 \mathrm{~mL}, 0.1 \mathrm{mmol} / \mathrm{L})$. The solution was incubated for $120 \mathrm{~min}$ and absorbance was measured by ShimadzU UV1280 UV-VIS spectrophotometer at the maximum wavelength of DPPH (Chen et al., 2016).

\section{Statistical analysis}

All data were subjected to one-way analysis of variance (ANOVA) using IBM SPSS Statistics 16 computer software at the level of significance of 0.05 .

\section{RESULT AND DISCUSSION}

\section{FT-IR Spectroscopic Analysis}

Figure 1 showed FT-IR spectra from raw (A), heat-treated (B), chemical-treated ie. alginate $+\mathrm{H}_{2} \mathrm{O}_{2}(\mathrm{C})$, and $\mathrm{H}_{2} \mathrm{O}_{2}+$ ascorbic acid (D) alginate compared to the standard alginate (Sigma, USA). The characteristic bands for the $\mathrm{OH}$ stretching vibration were observed at 3431, 3420, 3420, and $3419 \mathrm{~cm}^{-1}$, respectively. It is worth mentioning that bands appearing in the region of $3400 \mathrm{~cm}^{-1}$ belong to all types of hydrogen-bonded $\mathrm{OH}$ groups. The bands appeared at 1656, 1657, 1652, $1656 \mathrm{~cm}^{-1}$ and 1437, 1436, 1436, $1436 \mathrm{~cm}^{-1}$ belong to the asymmetric and symmetric COO- stretching vibrations, respectively. The main bands revealed were positioned around 1315, 1021, $953 \mathrm{~cm}^{-1}$ which could be attributed to deformation vibration of the $\mathrm{C}-\mathrm{C}$ band, stretching vibration of $\mathrm{C}-\mathrm{O}-\mathrm{C}$, and $\mathrm{O}-\mathrm{H}$ bending vibration of alginate. The band about $1315 \mathrm{~cm}^{-1}$ could be attributed to the C$\mathrm{OH}$ stretching vibration, while 1021 and 953 $\mathrm{cm}^{-1}$ to $\mathrm{O}-\mathrm{H}$ bending vibration of alginate (Safi et al., 2007; Xiao et al., 2014).

Overall, there were not change in the spectra pattern and no additional bands appeared with the different degradation methods. However, there were some differences could be observed in the height and shape of each absorbed band. The peak broad absorbance band approximately at $3400 \mathrm{~cm}^{-1}$ wave number was reduced by the heating method and decreased by the chemical method. Visually, in the combined of alginate with hydrogen peroxide method was a slightly expanded in the wavenumber of $3400 \mathrm{~cm}^{-1}$, which is quite visible compared to raw and other degradation methods, also related to the $\mathrm{O}-\mathrm{H}$ bonding. This method enables the bonding of $\mathrm{O}-\mathrm{H}$ tends to be

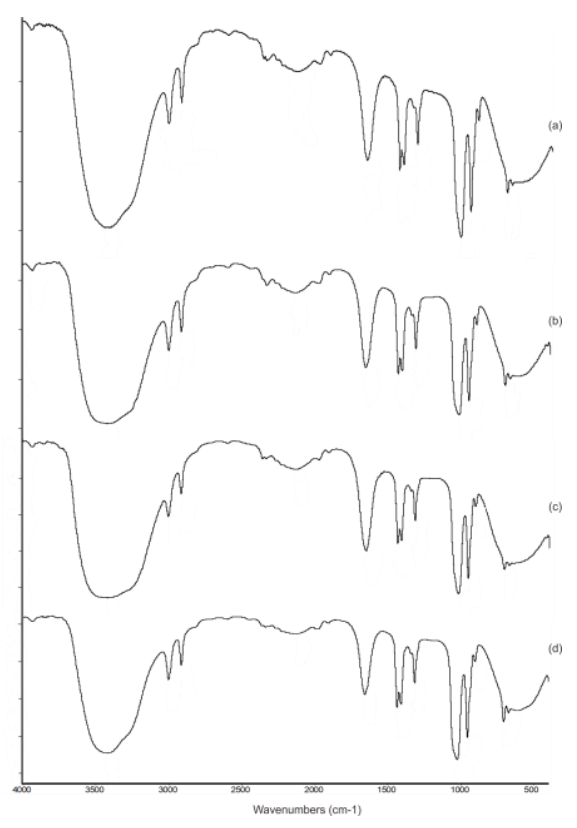

Figure 1. The FT-IR spectra of raw (A), 4.5h heat-treated (B), alginate $+\mathrm{H}_{2} \mathrm{O}_{2}(\mathrm{C})$, alginate $+\mathrm{H}_{2} \mathrm{O}_{2}+$ ascorbic acid (D) from Sargassum sp. 
unstable for antioxidant properties than other methods. At the $3400 \mathrm{~cm}^{-1}$ wavenumbers, the transmittance of raw alginate and the degradation methods were reduced $(35,25$, $15,10 \%)$ respectively. These characteristics reveal the fact that the antioxidant activity is largely contributed by hydrogen cations which play a role in inhibiting free radicals. Furthermore, there is a marked difference in absorbance intensity of about $1600 \mathrm{~cm}^{-1}$ and slightly different characteristics in the fingerprint area $\left(750-950 \mathrm{~cm}^{-1}\right)$ but in the same wave range, sodium alginate category (948; $894 \mathrm{~cm}^{-1}$ ) (Yudiati \& Isnansetyo, 2017).

\section{UV-visible Spectroscopic Analysis}

Figure 2 shows the UV absorption spectra from raw, heat-treated, and two chemical-treated. The raw alginate showed a sloping spectra pattern. The combination method of alginate and hydrogen peroxide was formed a new pattern at about $250 \mathrm{~nm}$, followed by a combination of the alginate method plus hydrogen peroxide and ascorbic acid.

The heating method begins to form peaks and valleys ranging from 270 and 250 $\mathrm{nm}$ accompanied by increasing absorption intensity. It was explained this peak can be ascribed to double bonds formed after the main chain scission of the polymer followed by the ring-opening (Nagasawa et al., 2000).
It is consistent with previous results where two peaks were observed and ascribed to carbonyl and carboxyl groups (Ulański \& Rosiak, 1992).

\section{DPPH radical scavenging activity}

DPPH is a stable free radical compound. In this study showed maximum absorbance of DPPH at $516 \mathrm{~nm}$ (Figure 3). It was commonly used in assessing antioxidant activity. The DPPH assays were expressed in $I_{50}$ values. The concentration of the sample necessary to decrease the initial concentration of DPPH by $50 \%\left(\mathrm{IC}_{50}\right)$ under the experimental condition was determined (Johnson et al 2019). Therefore, the lower value of $I_{50}$ indicates a higher antioxidant activity (Sivaraman et al., 2013). The DPPH scavenging effect of alginate with the degradation method was higher than raw alginate, however, both showed lower scavenging activity than ascorbic acid (Chen et al., 2016). The $I_{50}$ values of Treatment $A$, Treatment C were, 40.86 ppm, 196.15 ppm, respectively. The alginate structure of Treatment $C$ may be damaged due to the destructive properties of hydrogen peroxide which is a strong oxidizing agent. This is confirmed by Zhang et al. (2013), in that method, there was only one degradation reagent, $\mathrm{H}_{2} \mathrm{O}_{2}$, which was unstable and unrepeatable. Therefore, in this study we tried to combined $\mathrm{H}_{2} \mathrm{O}_{2}$ and ascorbic acid to be

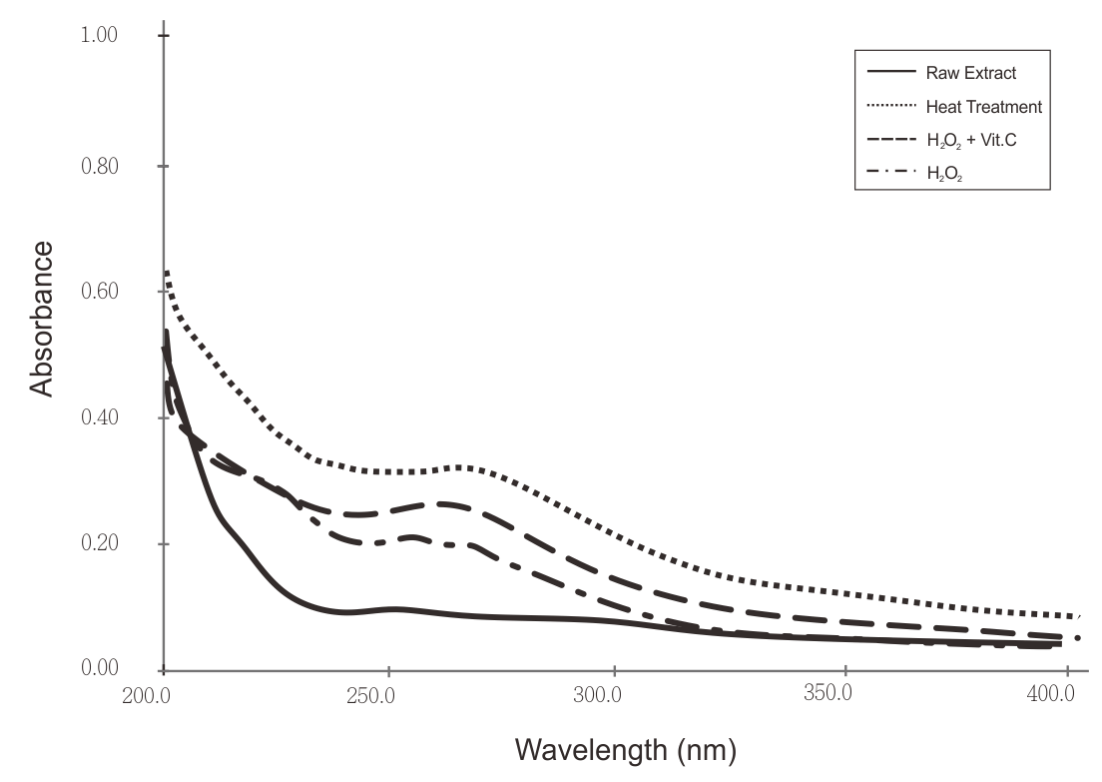

Figure 2. UV absorption spectra for raw alginate, heat-treated and two chemical-treated 


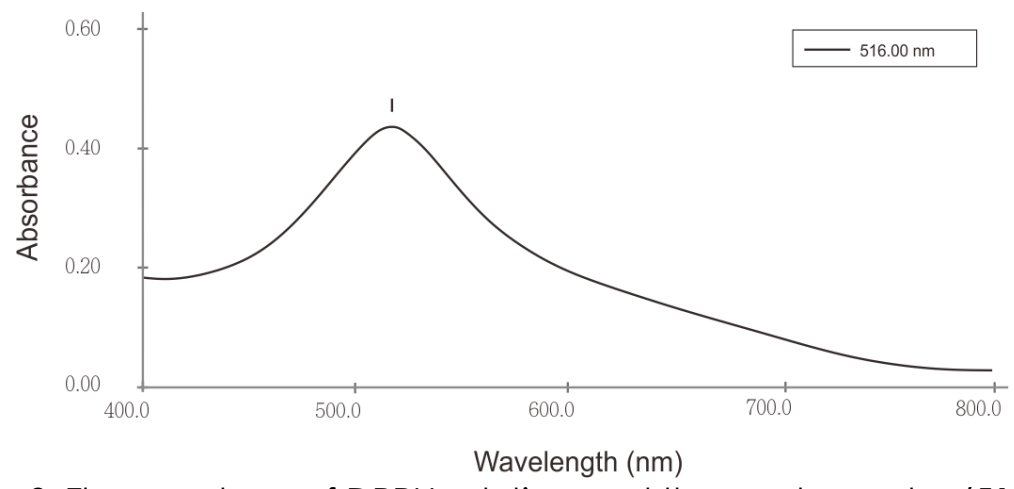

Figure 3. The spectrum of DPPH solution and the peak spectra $(516 \mathrm{~nm})$

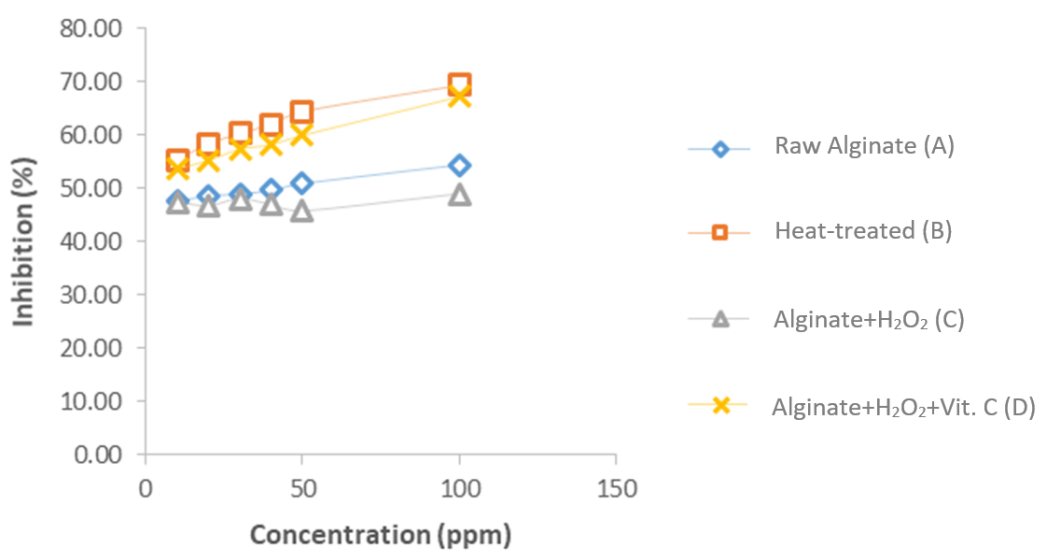

Figure 4. The antioxidant activities of Sargassum sp. in different degradation techniques

the degradation reagent, referring to the ability of ascorbic acid which can reduce $\mathrm{H}_{2} \mathrm{O}_{2}$ to produce hydroxyl radicals in the presence of trace metals (Chen et al., 2016).

Also, the scavenging effect of Treatment B and Treatment D was determined to be $55.39 \%$ and $53.71 \%$ even at $10 \mathrm{ppm}$. Research from Yudiati et al. (2018) and Chen et al. (2016) supported a similar phenomenon. The heat treatment and combined $\mathrm{H}_{2} \mathrm{O}_{2}$ plus ascorbic acid alginates are showed higher the DPPH radical scavenging activity than the raw alginates. The results suggest that oligosaccharides alginate may expose more active moieties, which could serve as hydrogen donors to scavenge DPPH radicals.

\section{CONCLUSION}

Efforts to increase the ability of antioxidants by adding $\mathrm{H}_{2} \mathrm{O}_{2}+$ ascorbic acid for alginate degradation showed from the raw alginate sample (40.86 ppm). These results were not significantly different $(p>0.05)$ from the heating method. The combination of alginate and hydrogen peroxide showed the lowest activity (196.15 ppm) ( $p<0.05)$. Efforts to develop oligosaccharide alginate can be potential in the fields of medicine, cosmetics, and food production.

\section{ACKNOWLEDGMENT}

The authors would like to thank the Ministry of Research and Technology for providing research funds of Master's Thesis Scheme, contract no. 225-39/UN7.6.1/PP/2020 and to all those who have kindly helped us to support this research at The Tropical Marine Biotechnology Laboratory and Biology Laboratory, Diponegoro University.

\section{REFERENCES}

Addina, S., Subaryono, S. \& Sukarno, S. 2020. Aktivitas Oligosakarida Alginat Sebagai 
Antioksidan dan Inhibitor Alfa glukosidase. J. Pascapan. Bioteknol. Kel. Perikan., 15(1):47-61. doi: 10.15578/jpbkp. v15il.646.

Borazjani, N.J., Tabarsa, M., You, S. \& Rezaei, M. 2017. Effects of extraction methods on molecular characteristics, antioxidant properties and immunomodulation of alginates from Sargassum angustifolium. Int. J. Biolog. Macromol., 101:703-711. doi: 10.1016/j.ijbiomac.2017.03.128.

Chen, B.J., Shi, M.J., Cui, S., Hao, S.X., Hider, R.C. and Zhou, T. 2016. Improved antioxidant and anti-tyrosinase activity of polysaccharide from Sargassum fusiforme by degradation. Int. J. Biolog. Macromol., 92:715-722. doi: 10.1016/j.jjbiomac.2016. 07.082

Chen, J., Hu, Y., Zhang, L., Wang, Y., Wang, S., Zhang, Y., Guo, H., Ji, D. \& Wang, Y. 2017. Alginate oligosaccharide DP5 exhibits antitumor effects in osteosarcoma patients following surgery. Front. Pharm acol., 8:623. doi: 10.3389/fphar.2017.006 23.

Cherng, J.H. 2018. Calcium Alginate Polysaccharide Dressing as an Accelerated Treatment for Burn Wound Healing. In Wound Healing. Intech. Open. doi : 10.5772/intechopen.80875.

Dodero, A., Vicini, S. \& Castellano, M. 2020. Depolymerization of sodium alginate in saline solutions via ultrasonic treatments: A rheological characterization. Food Hydrocoll., 106128. doi: 10.1016/j.food hyd.2020.106128.

Fawzy, M.A., Gomaa, M., Hifney, A.F. \& Abdel-Gawad, K.M. 2017. Optimization of alginate alkaline extraction technology from Sargassum latifolium and its potential antioxidant and emulsifying properties. Carbohydr. Polym., 157:19031912. doi: 10.1016/j.carbpol.201 6.11.077.

Fenoradosoa, T.A., Ali, G., Delattre, C., Laroche, C., Petit, E., Wadouachi, A. \& Michaud, P. 2010. Extraction and characterization of an alginate from the brown seaweed Sargassum turbinarioides Grunow. J. Appl. Phycol., 22(2):131-137. doi : 10.1007/ s1081 1-009-9432-y.

Johnson, M., Kanimozhi, S.A., Malar, T.R.J.J., Shibila, T., Freitas, P.R., Tintino, S.R., Menezes, I.R.A., da Costa, J.G.M. \& Coutinho, H.D.M. 2019. The antioxidative effects of bioactive products from Sargassum polycystum C. Agardh and Sargassum duplicatum J. Agardh against inflammation and other pathological issues. Complement. Ther. Med., 46:19-23. doi : 10.1016/j.ctim. 2019.06.014.

Kale, A.R. \& Nabunome, J. 2019. Ekstraksi alginat dari rumput laut coklat (Sargassum crassifolium) sebagai bahan enkapsulasi antioksidan dari ekstrak biji alpokat. Sainstek. 4(1):22-30.

Kelishomi, Z.H., Goliaei, B., Mahdavi, H., Nikoofar, A., Rahimi, M., MoosaviMovahedi, A.A., Mamashli, F. \& Bigdeli, B. 2016. Antioxidant activity of low molecular weight alginate produced by thermal treatment. Food Chem., 196:897902. doi: 10.1016/j.foodchem.20 15.09 .091

Liu, J., Yang, S., Li, X., Yan, Q., Reaney, M.J. \& Jiang, Z. 2019. Alginate oligosaccharides: production, biological activities, and potential applications. Comprehensive Compr. Rev. Food sci. Food Saf., 18(6):1859-1881. doi: 10.1111/1541-4337. 12494.

Nagasawa, N., Mitomo, H., Yoshii, F. \& Kume, T. 2000. Radiation-induced degradation of sodium alginate. Polym. Degrad. Stab. 69(3):279-285. doi: 10.1016/S0141-3910 (00)00070-7.

Sellimi, S., Younes, I., Ayed, H.B., Maalej, H.,

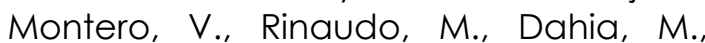
Mechichi, T., Hajji, M. \& Nasri, M. 2015. Structural, physicochemical and antioxidant properties of sodium alginate isolated from a Tunisian brown seaweed. Int. J. Biol. Macromol., 72:13581367. doi: 10.1016/j.ijbiomac.2014.10.016.

Safi, S., Morshed, M., Hosseini Ravandi, S.A. and Ghiaci, M. 2007. Study of electrospinning of sodium alginate, blended solutions of sodium alginate/poly (vinyl alcohol) and sodium alginate/poly (ethylene oxide). J. Appl. Polym. Sci. 104(5):3245-3255. doi: 10.10 02/app.25696.

Sari-Chmayssem, N., Taha, S., Mawlawi, H., Guégan, J.P., Jeftić, J. \& Benvegnu, T. 2016. Extracted and depolymerized alginates from brown algae Sargassum vulgare of Lebanese origin: chemical, rheological, and antioxidant properties. 
J. App. Phycol., 28(3):1915-1929. doi: 10.1007/s10811-015-0676-4.

Sivaraman A, Johnson M, Parimelazhagan T, \& Irudayaraj V. 2013. Evaluation of antioxidant potential of ethanolic extracts of selected species of Selaginella. Indian J. Nat. Prod. Resour., 4(3):238-244..

Ulański, P. \& Rosiak, J. 1992. Preliminary studies on radiation-induced changes in chitosan. Int. J. Radiat. Appl. Instrum. C Radiat. Phys. Chem., 39(1):53-57. doi: 10.1016/1359-0197(92)90171-B.

Yudiati, E. \& Isnansetyo, A. 2017. Characterizing the three different alginate type of Sargassum siliquosum. Indo. J. Mar. Sci., 22(1). doi: 10.14710/ik. ijms. 22. 1.7-14.
Yudiati, E., Pringgenies, D., Djunaedi, A., Arifin, Z. \& Sudaryono, A. 2018. Free radicals scavenging activities of low molecular weight sodium alginate (LMWSA) from Sargassum polycystum, produced by thermal treatment. Aquacul. Indo., 19(1):21-27. doi: 10.21534/ai.v19i1. 121.

Xiao, Q., Gu, X. \& Tan, S. 2014. Drying process of sodium alginate films studied by twodimensional correlation ATR-FTIR spectroscopy. Food Chem., 164:179-184. doi: 10.1016/j.foodchem.2014.05.044.

Zhang, Z., Wang, X., Mo, X. \& Qi, H., 2013. Degradation and the antioxidant activity of polysaccharide from Enteromorpha linza. Carbohydr. Polym., 92(2):2084-2087. doi: 10.1016/j.carbpol.2012.11.096. 